Zhou, Muzhi. 2017. Motherhood, employment, and the dynamics of women's gender attitudes. Gender \& Society. (forthcoming) DOI: 10.1177/0891243217732320

\title{
MOTHERHOOD, EMPLOYMENT, AND THE DYNAMICS OF WOMEN'S \\ GENDER ATTITUDES
}

\section{MUZHI ZHOU \\ St Antony's College \& University of Oxford, United Kingdom}

This article presents an investigation of the dynamics of women's gender attitudes from the perspective of women's conflicting employment and childrearing responsibilities. It examines the independent and joint effects of motherhood and employment on gender attitudes using combined data from the British Household Panel Survey and the Understanding Society panel study. The results of fixed effects models show no evidence supporting a direct influence of either motherhood or employment on women's attitudes toward a traditional division of labor. However, changes in attitudes are observed when motherhood and employment statuses are considered jointly. Specifically, women are less traditional after the transition to motherhood than before only if motherhood is combined with full-time employment. By contrast, women are more traditional after the transition to motherhood than before only if motherhood coincides with their withdrawal from the labor force. These associations remain robust after considering feedback from earlier attitudes. All the findings suggest that the emergence and realization of incompatibility between women's employment and childrearing responsibilities reshape women's gender attitudes during the transition to motherhood.

Keywords: attitude, family, gender, life course, motherhood

AUTHORS' NOTE: The author is deeply grateful to Francesco Billari, Jonathan Gershuny, Man Yee Kan, Melinda Mills, Oriel Sullivan, and the three anonymous reviewers for their helpful comments. The author also extends sincere thanks to the Swire Educational Trust for their financial support at St Antony's College. Correspondence concerning this article should be addressed to Muzhi Zhou, St Antony's College, 62 Woodstock Road, Oxford, OX2 6JF, United Kingdom; e-mail: muzhi.zhou@sant.ox.ac.uk. 
Zhou, Muzhi. 2017. Motherhood, employment, and the dynamics of women's gender attitudes. Gender \& Society. (forthcoming) DOI: 10.1177/0891243217732320

Women's growing participation in the labor market and the transformation of gender norms have inspired numerous studies examining people's views of the relationship between women and men and attitudes toward a gendered division of labor (Davis and Greenstein 2009). Views or attitudes regarding women and men's positions in the private and public spheres, which are usually referred to as gender attitudes, are important indicators of identity, and are correlated with individuals' family formation process, labor market performance, and participation in civic activities (Hakim 2000; Kan 2007; Paxton and Kunovich 2003).

Recent research has documented that gender attitudes change over the life course and are dependent on personal circumstances (Baxter et al. 2015; Vespa 2009). Among the critical life events and processes, the transition into parenthood is an essential stage in gender attitude construction because parenthood enhances the traditional division of labor. Childbirth, for example, coincides with an increase in women's share of housework and a reduction in the time spent in paid labor, whereas fatherhood barely changes men's time allocation (Killewald and García-Manglano 2016; Schober 2013b). Thus, motherhood is expected to facilitate the development of traditional gender attitudes. However, the relationship between motherhood and gender attitudes remains inconclusive. Both positive (Baxter et al. 2015; Corrigall and Konrad 2007; Fan and Marini 2000) and negative (Bolzendahl and Myers 2004; Kroska and Elman 2009) associations as well as no association (Davis and Moore 2010; Kaufman, Bernhardt, and Goldscheider 2016) between motherhood and traditional gender attitudes have been documented. Some studies suggest that the associations between motherhood and gender attitudes differ for women of different races, ethnicities, marital statuses, and economic resources, and for mothers who have different child care arrangements (Schober and Scott 2012; Vespa 2009). Although these studies demonstrate the importance of motherhood contexts, we still require a thorough discussion about one of the most 
Zhou, Muzhi. 2017. Motherhood, employment, and the dynamics of women's gender attitudes. Gender \& Society. (forthcoming) DOI: 10.1177/0891243217732320

fundamental elements that may alter women's gender attitudes, namely, the conflict between women's employment and childrearing responsibilities.

This article proposes that the conflict between women's employment and child-rearing responsibilities shapes the experience of motherhood and acts as a primary driver of gender attitude construction during adulthood. As modern welfare states have liberated women from their traditional caregiver role, women have increasingly endorsed the significance of their economic role, but they have remained constrained by gender norms and institutional contexts that emphasize women's role as care-givers (Esping-Andersen 2009; McDonald 2000). Little quantitative research has examined the intersection or interaction between motherhood and employment. Employment is either treated as an additive statistical control (Cunningham et al. 2005; Kroska and Elman 2009) or not included in modeling (Baxter et al. 2015; Kaufman, Bernhardt, and Goldscheider 2016). A few studies that examine the effect of maternal employment attribute changes in attitudes to inconsistency between prenatal attitudes and postnatal arrangements rather than to the incompatibility between employment and childrearing responsibilities that women generally face (Schober and Scott 2012). Moreover, studies remain vague about the extent to which the experience of motherhood affects attitudes rather than vice versa. Without a clear understanding of the independent and joint effects of motherhood and employment, the critical mechanism that guides the construction of women's gender attitudes tends to be ignored, thereby increasing the risk of misrepresenting variations in gender attitude during adulthood.

Using combined longitudinal data from the British Household Panel Survey (BHPS) and the Understanding Society panel study (USoc) covering the period from 1991 to 2013, I examine within-individual changes in gender attitudes using a fixed effects regression method. 
Zhou, Muzhi. 2017. Motherhood, employment, and the dynamics of women's gender attitudes. Gender \& Society. (forthcoming) DOI: 10.1177/0891243217732320

In addition to the independent association of gender attitudes with motherhood and employment, I also analyze the relationship between attitudes and the interaction of motherhood and employment. To investigate potential alternative explanations, I examine whether the effect of motherhood results from differences in women's employment characteristics before and after childbirth. I further assess whether the effects of the combined status of motherhood and employment persist after integrating feedback from earlier attitudes. This study is the first to consider both time-invariant confounders and feedback from attitudes to evaluate the effect of the combined status of motherhood and employment on gender attitudes. This work raises the important issue of the reconstruction of women's gender attitudes during adulthood and offers novel explanations of the relationship between women's gender attitudes and women's employment and motherhood statuses.

\section{MOTHERHOOD, EMPLOYMENT, AND WOMEN'S GENDER ATTITUDES}

In this section, I first review related theories and summarize previous empirical work on the independent role of motherhood and employment in shaping gender attitudes. I then explain the need to consider the joint effects of motherhood and employment on women's gender attitudes.

\section{Motherhood and Gender Attitudes}

Women's role as mothers is commonly associated with traditional gender attitudes. Identity theory suggests that by interacting with others, individuals receive, interpret, and internalize the behavioral expectations that are attached to the social positions they occupy (Stryker 1968; Stryker and Burke 2000). The dominant social expectation of mothering overlaps with traditional norms of the gendered division of labor. For example, good mothering is often characterized as "full-time, stay-at-home mothering" (Boris 1994). 
Zhou, Muzhi. 2017. Motherhood, employment, and the dynamics of women's gender attitudes. Gender \& Society. (forthcoming) DOI: 10.1177/0891243217732320

Although such expectations have been weakened in recent decades, the ideology of intensive mothering that embodies child-centered, expert-guided, time-consuming, and financially demanding values is gaining momentum (Hays 1996, 46; Johnston and Swanson 2006).

These expectations echo the permanence of the normative assumption of men as primary providers and women as caregivers. Both stay-at-home and employed women internalize the values and expectations of motherhood. They prioritize their children's needs and acknowledge the necessity of maintaining primary responsibility for children (Garey 1999; Hays 1996; Mercer 2004). Accordingly, mothers are expected to be more traditional than childless women (hypothesis 1).

This explanation focuses on the internalization of women's role as caregivers. It assumes that women are inclined to accept and perform their traditional role as caregivers when required. It also implicitly implies that the significance of a woman's identity as a worker is undermined when women hold the primary responsibility for childcare. However, empirical studies find that women's primary caregiver role following childbirth may not necessarily dominate their identity. In particular, the work commitments or career aspirations of working mothers remain stable before and after childbirth (Evertsson 2013; Yavorsky, Kamp Dush, and Schoppe-Sullivan 2015). Therefore, focusing on role of mothers as caregivers overlooks the significance of employment in forming women's identities and attitudes.

\section{Employment and Gender Attitudes}

Two approaches - the interest-based explanation and the exposure-based explanationare commonly used to interpret the relationship between gender attitudes and employment status. The interest-based approach argues that when an individual's interest benefits from certain gender attitudes, the individual is likely to maintain those attitudes (Bolzendahl and 
Zhou, Muzhi. 2017. Motherhood, employment, and the dynamics of women's gender attitudes. Gender \& Society. (forthcoming) DOI: 10.1177/0891243217732320

Myers 2004). Therefore, employed women are inclined to support gender egalitarianism because this idea benefits them in terms of increased earnings, more promotion opportunities, and less workplace discrimination and harassment. The exposure-based approach argues that exposure to views or situations that are consonant with gender-egalitarianism encourages egalitarian attitudes (Bolzendahl and Myers 2004). The workplace provides additional nontraditional role models, offers an environment that welcomes new ideas, and increases women's confidence in and expectations for financial independence (Davis and Robinson 1991; Kroska and Elman 2009). In summary, both the interest- and exposure-based explanations predict that employment liberalizes women's gender attitudes. Nonworking women are expected to be more traditional than working women (hypothesis 2).

Although empirical evidence largely indicates that non-working women are more traditional compared to employed women, the findings are not always consistent. In particular, the effect of employment is dependent on the age when the relationship is measured. Non-working women are more traditional than employed women only after early adulthood, but the corresponding effect is not observed for men (Corrigall and Konrad 2007; Cunningham et al. 2005; Fan and Marini 2000). This age- and gender-specific effect of employment implies that certain life course events, such as childbirth, may interact with women's labor market activity and generate the observed association between employment and gender attitudes.

The interest- and exposure-based explanations focus exclusively on the role of employment, overlooking how the presence of a young child alters the experience and meaning of employment. The main reason that many women leave employment is to care for children. Thus, it may be misleading to assume that the effect of women's employment is 
Zhou, Muzhi. 2017. Motherhood, employment, and the dynamics of women's gender attitudes. Gender \& Society. (forthcoming) DOI: 10.1177/0891243217732320

independent of their motherhood status.

\section{The Joint Effect of Motherhood and Employment on Gender Attitudes}

Although growing opportunities and improved gender equality in the labor market offer apparent gains and attract women's participation, women continue to face substantial demands on their time and efforts to provide childcare. In the United Kingdom, for example, family policies have historically exhibited a strong emphasis on the family's childcare responsibilities. Maternity leave is generous, with a maximum of 52 weeks currently permitted. In contrast, formal childcare services are inadequate and costly (Schober 2013a). Women's employment decisions are thus bound to their childrearing responsibilities. In 2013, the U.K. employment rates for women and men without independent children were similar, but the rate was much lower for women with dependent children (Office for National Statistics 2013). In 2014, 60.9 percent of women with dependent children aged under five were working, of whom 57.7 percent were working part time (Office for National Statistics 2014). In this context of limited institutional support for combining employment and childrearing responsibilities, the inextricably intertwined relationship between motherhood and employment can be understood as the root of gender attitude adjustments.

Women's employment and motherhood statuses should be jointly considered. The “coming together" of women's economic and caregiver roles places women in novel conditions during the transition into motherhood. The emerging conflict between women's work and childrearing responsibilities may challenge women's previous views about women and men's relative positions in the private and public spheres and provoke adjustments in gender attitudes through several psychological processes. For example, women can rationalize their decisions and behaviors by minimizing the cognitive dissonance that results 
Zhou, Muzhi. 2017. Motherhood, employment, and the dynamics of women's gender attitudes. Gender \& Society. (forthcoming) DOI: 10.1177/0891243217732320

from inconsistency between their prenatal gender attitudes and their maternal employment and childrearing arrangements (Baxter et al. 2015; Festinger 1962). They may mentally discount the desirability of the unachieved alternative (Elster 2016) or reframe available options (Baxter and Montgomery 1996). Thus, the reconstruction of women's gender attitudes during the transition to motherhood is dependent on how women organize, combine, or differentiate their dual roles as caregiver and worker. It is necessary to consider how employment alters the experience of motherhood as well as how motherhood reshapes the meaning of employment.

The experience and meaning of employment differ substantially for childless women and mothers. For childless women, the degree of conflict between employment and family responsibilities is much lower than that for mothers. Changes in employment status arise most likely from reasons other than the need to fulfill the traditional caregiver role and thus are less likely to prompt a re-evaluation of gender attitudes.

By contrast, full-time employment makes mothers particularly susceptible to both workfamily conflict and workplace discrimination (Chatterji, Markowitz, and Brooks-Gunn 2013). Full-time employment is likely to constrain women's role as the primary caregiver. It is therefore necessary to maintain an intensified interest and belief in gender equality both at work and at home to counteract the demand to reduce women's labor market attachment. Working mothers are found to value highly the benefits of employment and to underestimate its costs. They also are more likely to mention parenting rather than mothering when describing mothering experiences (Boyd et al. 2016; Johnston and Swanson 2006). These findings reveal how women reframe the meaning of employment as mothers. Therefore, fulltime working mothers are more likely to have enhanced support for gender equality. 
Zhou, Muzhi. 2017. Motherhood, employment, and the dynamics of women's gender attitudes. Gender \& Society. (forthcoming) DOI: 10.1177/0891243217732320

Conversely, for stay-at-home mothers, the negative aspects of leaving the labor market, such as the loss of income, identity as a worker, and power at home, are substantial (Crompton and Lyonette 2005; Kanji and Cahusac 2015). Similarly, the importance of the worker role for part-time working mothers is undermined to care for the family. These women may have to adjust their preference to favor the traditional gendered division of labor and thus justify the reality of taking on the primary familial responsibilities. Berrington and her colleagues (2008) and Schober and Scott (2012) found that women's attitudes become more traditional when they reduced their hours of work after childbirth, and that this effect is particularly prominent among women who were strongly liberal before childbirth. These authors explained this result from a cognitive dissonance perspective. Therefore, nonworking and part-time working motherhood should have a traditionalizing effect on women's attitudes.

The above analysis predicts that women's gender attitudes are dependent on the combined status of motherhood and employment. Full-time working and non-working mothers adapt their gender attitudes in opposite directions, but a change in employment status for childless women is less likely to be associated with a change in gender attitudes. The liberalizing effect of employment thus depends on women's motherhood status, and this effect should be more significant for mothers than for childless women (hypothesis 3). Moreover, the effect of motherhood is dependent on women's maternal employment decisions. Specifically, full-time working women are expected to be less traditional after transitioning to motherhood than they are before (hypothesis $4 a$ ), whereas non-working and part-time working women should be more traditional after the transition to motherhood than they are before (hypothesis 4b). 
Zhou, Muzhi. 2017. Motherhood, employment, and the dynamics of women's gender attitudes. Gender \& Society. (forthcoming) DOI: 10.1177/0891243217732320

\section{ANALYSIS PLAN}

The data used are from the BHPS and the USoc survey that incorporates the BHPS sample (University of Essex 2010, 2016). In 1991 (first wave), the BHPS recruited 5,500 households from Great Britain and conducted approximately 10,000 individual interviews. Extension samples in Scotland and Wales and in Northern Ireland were included in 1999 and 2001, respectively. From the year of entry, household members aged 16 or older were interviewed and then re-interviewed in successive years. Gender attitudes were measured in alternate waves starting in 1991 for individuals who completed a face-to-face interview (95 percent of all interviews). This design offers a unique opportunity to capture changes in attitudes over the life course.

In each wave, I select women aged 21 to 45 who are most likely to have completed education and to have children. Waves without gender attitude information are excluded. There are 32,740 person-year observations for 8,724 women. To capture the period with the highest level of incompatibility between women's employment and childrearing responsibilities, observations of women with a youngest child older than five are excluded. This procedure leaves 22,939 person-year observations for 7,539 women. After removing observations with missing information, 7,339 individuals remain. Of these, 66.6 percent have repeated observations, and I analyzed these observations. I conducted multiple analyses using less or more restrictive samples and did not find that selections into wave non-response altered the conclusion. ${ }^{1}$ Because the transition to motherhood is the key event, I also excluded individuals who already had a child at the time of their first interview. Ultimately, there are 12,562 person-year observations and 2,729 individuals who either remained childless or experienced the transition to motherhood during the observational period. 
Zhou, Muzhi. 2017. Motherhood, employment, and the dynamics of women's gender attitudes. Gender \& Society. (forthcoming) DOI: 10.1177/0891243217732320

\section{Dependent Variable}

Gender attitude is measured by a score indicating the level of support for a traditional gendered division of labor. Higher scores refer to attitudes that are more traditional.

Respondents selected their levels of agreement or disagreement with several statements

(Table 1) on a five-point Likert scale: strongly agree, agree, neither agree nor disagree, disagree, and strongly disagree. These statements in Table 1 have been widely used in other nationally representative surveys and studies to construct gender attitudes (for a review, please refer to Davis and Greenstein 2009). The BHPS contains six statements, and the USoc survey retains four of them (items 1, 2, 4, and 6). I first evaluated all six items using principal factor analysis to determine whether I could treat all six items equally (Table 1). This analysis identifies two factors: items 1, 2, and 6 in one group and items 3, 4, and 5 in the other group. Factor 1 is superior because of its higher eigenvalue than that of Factor 2, which measures the variance of that factor. The eigenvalue for Factor 2 is smaller than one, indicating that Factor 2 accounts for a smaller amount of variance as a single variable and does not constitute a good factor based on the Kaiser criterion (Kaiser 1958). The internal reliability measured by Cronbach's $\alpha$ for items 3, 4, and 5 is also lower (ranging from 0.606 to 0.677 ) than for items 1, 2, and 6 (0.745 to 0.808). Several studies also report that items such as those in Factor 2 that measure attitudes toward gender egalitarian statements are insufficient to differentiate traditional and non-traditional respondents (Barth 2016; Braun 2008). The final score, which is the summed score of the responses for items 1, 2, and 6, ranges from three to 15 (see also Lersch 2016; Schober and Scott 2012). It has an un-weighted mean value of 7.052, a between-individual standard deviation of 2.071, and a within-individual standard deviation of 1.391. ${ }^{2}$ I standardized this traditional attitude score to have a mean of zero and a standard deviation of one. Therefore, the effects of the explanatory variables reported in the following 
Zhou, Muzhi. 2017. Motherhood, employment, and the dynamics of women's gender attitudes. Gender \& Society. (forthcoming) DOI: 10.1177/0891243217732320

results are expressed in standard deviation units.

[Table 1]

\section{Independent Variables}

Motherhood Status. A binary variable indicating whether an individual has any children at the time of interview represents motherhood status. Childless status is assigned a value of zero. ${ }^{3}$

Employment Status. Women's employment status is classified into full-time employment (working 30 hours or more per week) (reference group), part-time employment (working less than 30 hours per week), and non-working.

Interaction between Motherhood and Employment Statuses. The combined status of motherhood and employment is considered by including interactions between motherhood and employment statuses. The non-working status for mothers is further divided into mothers on maternity leave and non-working mothers. Thus, there are four categories after the transition to motherhood: full-time working mothers, part-time working mothers, mothers on maternity leave, and non-working mothers. There are three employment categories for childless women: full-time working childless women (reference group), part-time working childless women, and non-working childless women.

Control variables. Age, marital status, and educational attainment are likely to correlate with gender attitudes and the transition to motherhood as well as participation in the labor market (Fan and Marini 2000; Guetto, Luijkx, and Scherer 2015). Marital status is classified into single and never married, living as a couple, married, and divorced/separated/widowed. Educational level is coded as first degree or above, some higher qualifications, and General Certificate of Secondary Education (GCSE) level or lower. ${ }^{4}$ Wave numbers are included as 
Zhou, Muzhi. 2017. Motherhood, employment, and the dynamics of women's gender attitudes. Gender \& Society. (forthcoming) DOI: 10.1177/0891243217732320

dummy variables to control for period-specific factors.

\section{Methods}

One key challenge in studying the relationship between attitudes and life experience is to distinguish the effect of parenthood on gender attitudes from selectivity associated with both. Egalitarian women, for instance, are less likely to have a child and more likely to participate in the labor market (Hakim 2000; Holland and Keizer 2015). Thus, time-constant characteristics such as personality, lifestyle preferences, and overall attitude toward the gendered division of labor may confound the observed relationship between women's fertility and/or employment behaviors and attitudes.

I used fixed effects linear regressions to estimate the effects of motherhood, employment, and the combined status of motherhood and employment on women's gender attitudes. This method identifies the effect of motherhood and/or employment on gender attitudes by comparing the attitude scores of the same individual with different motherhood and/or employment statuses. Because the fixed effects specifications consider only intra-person change, there is no need to control for person-specific, time-invariant factors such as race, class background, or stable preferences. The fixed effects regression uses within-individual variations by demeaning the dependent and independent variables from person-specific means, thereby deleting time-invariant factors. This method also cancels out measurement errors caused by people who persistently misreport their attitudes. Previous studies have used this method to study the association between gender attitudes and specific life events, such as getting married or having children (Baxter et al. 2015; Kim and Cheung 2015; Vespa 2009). 
Zhou, Muzhi. 2017. Motherhood, employment, and the dynamics of women's gender attitudes. Gender \& Society. (forthcoming) DOI: 10.1177/0891243217732320

\section{THE EFFECT OF MOTHERHOOD AND EMPLOYMENT ON WOMEN'S GENDER ATTITUDES}

\section{Descriptive Analysis}

Table 2 reports the weighted descriptive statistics of the selected sample. During the observational period, 1,150 of 2,729 women (42.1 percent) became mothers for the first time. Of the childless women, 90.1 percent worked full time at some point, 20.0 percent had parttime working experience, and 23.4 did not work at some point in time. Among mothers, 40.4 percent had full-time working experience, more than half worked part time at some point, and 39.3 percent did not work at some point. With respect to the person-wave observations, mothers had more traditional gender attitudes than childless women. Of the childless personwave observations, 81.8 percent reflected full-time working status, whereas approximately one-quarter of the observations for mothers recorded full-time employment.

[Table 2]

Table 3 presents the mean of the traditional gender attitude score by motherhood and employment statuses for the 1,150 women who experienced the transition to motherhood.

Differences in the mean attitude score across groups were evaluated using t-tests. Women had higher scores or held attitudes that are more traditional after the transition to motherhood than before (last column). Moreover, there is substantial heterogeneity across cells where motherhood and employment statuses are jointly considered. Women as full-time working mothers had the lowest score. Mothers in other employment groups held more traditional attitudes than childless women who worked full time. Non-working mothers showed the most support for the traditional gendered division of labor, with a score of 8.791. In summary, the overall increase in traditional gender attitudes after the transition to motherhood obscures the 
Zhou, Muzhi. 2017. Motherhood, employment, and the dynamics of women's gender attitudes. Gender \& Society. (forthcoming) DOI: 10.1177/0891243217732320

true variation in attitudes across groups in which motherhood and employment statuses intersect differently.

[Table 3]

\section{Multivariate Analysis}

Table 4 reports the estimates of the key variables from the fixed effects regression models. Model 1 indicates an increase of 0.044 standard deviations (SDs) on average in the traditional gender attitude score after the transition to motherhood than before. The size of this estimate is small but nevertheless statistically significant at the 0.05 level $(p=.047)$. Therefore, without considering changes in employment status after the transition to motherhood, motherhood seems to have an overall weak traditionalizing effect on gender attitudes. Model 2 evaluates attitude change associated with the transition to motherhood by removing any effects resulting from changes in employment status. The estimate for motherhood status is now close to zero. Employment status completely mediates the association between motherhood and traditional gender attitudes. Thus, the direct traditionalizing effect of motherhood as predicted by hypothesis 1 is not supported. Model 2 also reports that a change from full-time employment to non-working status is associated with a $0.186 \mathrm{SD}$ increase in the traditional gender attitude score $(\mathrm{p}<.001)$. This result seems to support hypothesis 2 .

[Table 4]

To evaluate whether the liberalizing effect of employment is dependent on motherhood status, Model 3 includes the interaction terms of motherhood status and employment status. First, the main effect of motherhood (when employment status is full-time) is significantly 
Zhou, Muzhi. 2017. Motherhood, employment, and the dynamics of women's gender attitudes. Gender \& Society. (forthcoming) DOI: 10.1177/0891243217732320

negative, which contradicts hypothesis $\mathbf{1}$. Second, the main effect of employment (when motherhood status is childless) is limited because the liberalizing effect of employment is not observed for childless women. Rather, the sign of the estimate of childless part-time employment is negative. This estimate is statistically significant at the 0.05 level $(p=.019)$, although its magnitude is small. In other words, childless women who work part time exhibit slightly less traditional attitudes compared to working full time. Further analysis (not shown here) revealed that this result is driven by full-time students who are classified as part-time workers. Thus, no evidence suggests that employment per se has a liberalizing effect on gender attitudes for childless women, which contradicts hypothesis $\mathbf{2}$.

A comparison of Models 2 and 3 suggests that the liberalizing effect of employment is driven by its effect among mothers. The shifts from full-time working motherhood to parttime working motherhood and non-working motherhood are associated with a 0.226 SD $(0.300-0.074)$ and a $0.540 \mathrm{SD}(0.573-0.033)$ increase in the traditional gender attitude score (both $\mathrm{p}<.001$ ). The Wald test shows that the estimate of part-time working motherhood is statistically significantly different from that of non-working motherhood ( $p<.001)$. To further demonstrate the varying effect of employment for childless women and mothers, I plotted the estimated coefficients and their confidence intervals for women of different employment statuses when they are childless or mothers—-see Figure 1. This figure indicates that childless women's gender attitudes change only slightly with a change in employment status. However, as mothers enter or exit the labor market, their attitudes vary substantially. The considerably more significant differences in gender attitudes across employment groups for mothers than for childless women support hypothesis 3.

[Figure 1] 
Zhou, Muzhi. 2017. Motherhood, employment, and the dynamics of women's gender attitudes. Gender \& Society. (forthcoming) DOI: 10.1177/0891243217732320

Given that most women work full time before having children, and given that there is no substantial difference in gender attitudes across employment groups among childless women, Model 4 uses childless full-time working status as the reference group to represent a common status before the transition to motherhood. In addition, maternity leave, which is grouped into the non-working status in earlier models, is separated as an independent category. This model provides a realistic picture of the dynamics of women's gender attitudes during the transition to motherhood.

Women as full-time working mothers score 0.212 SDs lower than when they are childless full-time workers. Hypothesis 4a is thus supported. Non-working mothers score 0.350 SDs higher after the transition to motherhood than when they are childless full-time workers. There is no statistically significant change in the attitude score when women become parttime working mothers $(\mathrm{p}=.433)$. Hypothesis $\mathbf{4 b}$ is supported except for the prediction concerning part-time working motherhood. In addition, women do not change their traditional gender attitudes when they are on maternity leave $(p=.922)$. This result again confirms that childbirth per se is not associated with changes in gender attitudes.

\section{Testing Alternative Explanations and Reciprocal Effects}

Because fixed effects models do not account for unmeasured time-varying covariates, some time-varying confounders could be responsible for the observed associations. This section discusses issues that may challenge the above findings and presents two tests to examine the robustness of the main results.

First, the negative association between full-time working motherhood and traditional gender attitudes may result from changes in women's employment characteristics after 
Zhou, Muzhi. 2017. Motherhood, employment, and the dynamics of women's gender attitudes. Gender \& Society. (forthcoming) DOI: 10.1177/0891243217732320

childbirth. Gangl and Ziefle (2009) found that British mothers are more likely to be employed in the public sector or to move to occupations with a higher proportion of female workers. Compared with the private sector, the public sector usually provides a more supportive family-work culture, better-implemented family-friendly policies, and more flexible time schedules (Wayne et al. 2013). From an exposure-based perspective, this type of environment is more likely to alleviate the work-family conflict and enhance employee commitment, thereby inspiring less traditional attitudes. To test this explanation, I selected person-wave observations recording full-time employment status and created three job characteristic indicators. The first indicator is the employment sector, which includes the private sector and others. Following Gangl and Ziefle's work (2009), the percentage of female workers in a current occupation at the three-digit level of the International Standard Classification of Occupations (ISCO-88) is used to represent female occupation. The third indicator is a binary variable representing whether women are self-employed. The control variables are the same as those specified in the previous models. The results from Table 5 show that none of the three employment indicators is statistically significant (Model 2). The size and significance level of the estimated coefficient of motherhood among full-time workers remain unchanged after considering job characteristics. Thus, changes in job characteristics cannot account for the observed association between full-time working motherhood and traditional gender attitudes.

[Table 5]

A more serious challenge is that the observed associations between the combined status of motherhood and employment and attitudes may be driven by the influence of gender attitudes on women's maternal employment behaviors. Women may make a particular 
Zhou, Muzhi. 2017. Motherhood, employment, and the dynamics of women's gender attitudes. Gender \& Society. (forthcoming) DOI: 10.1177/0891243217732320

decision about labor market participation because of recent changes in gender attitudes. In other words, changes in attitudes may lead to the transition to a specific combined status of motherhood and employment, not the other way around.

To infer the causal direction between attitudes and the combined status of motherhood and employment, I re-evaluated Model 4 in Table 4 using dynamic panel data modeling within a structural equation framework (Allison 2009; Williams, Allison, and Moral-Benito 2015). A great advantage of structural equation modeling (SEM) is that it is flexible and can relax strict exogeneity assumptions by allowing correlations between the current independent variables and error terms from earlier points in time. Using SEM, I could formulate the same Model 4 in Table 4 at each time point. I further included the lagged dependent variable as a predictor from the second person-wave, which enabled feedback from the lagged attitudes to the current attitudes. I also allowed attitudes from earlier points in time to correlate with the current combined status of motherhood and employment, which could not be achieved using conventional dynamic panel data modeling. These two measures account for feedback from the lagged values of attitudes toward the current combined status of motherhood and employment, thereby relaxing the strict exogeneity assumptions in conventional fixed effect models. The estimate of the combined status of motherhood and employment is the effect of specific motherhood experience on attitudes after controlling for both person-specific fixed effects and feedback from earlier attitudes. Unfortunately, this approach required the use of a balanced sample. As an example, I selected 1,242 women who were interviewed for five waves or more. ${ }^{3}$ Table 6 reports the key estimates from the conventional fixed effects model using the demeaning method (the method to produce the results in Table 4), the maximum likelihood estimates of the fixed effects model using SEM (without accounting for feedback from earlier attitudes), and the maximum likelihood estimates of the dynamic, fixed effects 
Zhou, Muzhi. 2017. Motherhood, employment, and the dynamics of women's gender attitudes. Gender \& Society. (forthcoming) DOI: 10.1177/0891243217732320

model using SEM.

[Table 6]

First, the estimated coefficients of the first two models are almost identical. They also are similar to the estimates of Model 4 in Table 4. In fact, fixed effects models estimated with the conventional demeaning method yield results identical to those obtained using SEM (Allison 2009). Second, after taking into account feedback from the lagged values of attitudes, the estimated coefficients of full-time working and non-working motherhood change from 0.244 $(\mathrm{p}<.001)$ to $0.184(\mathrm{P}=.010)$ and from $0.364(\mathrm{p}<.001)$ to $0.297(\mathrm{p}=0.010)$, respectively. The reductions in the effect of full-time working and non-working motherhood imply changes in attitudes prior to the transition to the specific combined status of motherhood and employment. Nevertheless, the effects of full-time working and non-working motherhood remain statistically significant. I also used lagged independent variables to predict the traditional gender attitude scores using Model 4 in Table 4. The results are similar to the coefficients reported in the final model of Table 6 (available upon request). Consistent with other studies using a standard SEM without considering fixed effects (Berrington et al. 2008; Schober and Scott 2012), there is no evidence to indicate that feedback from attitudes would preclude the role of maternal employment in shaping women's gender attitudes.

\section{CONCLUSION}

In the current gender and social context of a high level of incompatibility between women's employment and childrearing responsibilities, this study theoretically and empirically contributes to the literature by evaluating various explanations for the dynamics of women's gender attitudes during adulthood. It proposes and demonstrates that conflicts 
Zhou, Muzhi. 2017. Motherhood, employment, and the dynamics of women's gender attitudes. Gender \& Society. (forthcoming) DOI: 10.1177/0891243217732320

between women's roles as mothers and workers are important factors in women's gender attitude construction during adulthood.

I found no direct influence of either motherhood or employment on women's attitudes toward the traditional division of labor. Other studies also note that childbirth per se is unlikely to influence women's gender attitudes (Berrington et al. 2008; Youngblut 1995). Therefore, the internalization of traditional expectations of motherhood may not be sufficiently powerful to alter women's gender attitudes. Similarly, employment itself is unlikely to impose a significant impact on these attitudes. I found the liberalizing effect of employment among mothers rather than among childless women. Thus the prediction of a liberalizing effect of employment that is independent of women's motherhood status based on the interest- and exposure-based explanations is not well supported.

Gender attitudes tend to change only when motherhood and employment statuses are considered jointly. Women become less traditional when they combine motherhood with fulltime employment, whereas they are more traditional when they withdraw from the labor market as mothers. These findings highlight the adaptive psychological process experienced by women to rationalize their decisions about work and family. More importantly, the findings lend strong support to an understudied reason for gender attitude adjustment: conflicts between women's economic and caregiver roles. Nevertheless, I find that women as part-time working mothers hold similar attitudes before and after the transition to motherhood. When women remain the primary caregivers, and when a cost-effective childcare substitute is absent, as in the United Kingdom, part-time employment is regarded as the most feasible way to reconcile employment and family responsibilities (Lewis et al. 2008), and the perceived level of work-family conflict resulting from part-time working motherhood may be minimal. 
Zhou, Muzhi. 2017. Motherhood, employment, and the dynamics of women's gender attitudes. Gender \& Society. (forthcoming) DOI: 10.1177/0891243217732320

In summary, the gross association between the transition to motherhood and changes in gender attitudes is the net outcome of all of the above changes in attitudes.

The findings of this study may be country-specific (i.e., specific to U.K. contexts), or they may be applicable to social contexts characterized by extensive maternity leave, insufficient and expensive formal childcare, and widespread part-time working opportunities. Moreover, motherhood, employment, and the combination of motherhood and employment may be associated with women's gender attitudes in different ways across countries with different gender norms and institutional settings. The conclusions of this study also are limited to women's attitudes toward the traditional division of labor. The attitude items used in this study, although highly reliable, impede a comprehensive understanding of people's attitudes toward gender. Research utilizing other reliable measurement items or methods, such as the implicit association test or the evaluative priming task that is widely applied in social psychology (Bohner and Dickel 2011), can extend our knowledge of the complexity of gender attitudes. Nevertheless, the items selected and analyzed in this study are valid and reliable measures of an important dimension of gender attitudes, and they are highly comparable to prior studies. Furthermore, this study focuses on women. Men's gender attitudes also may change during the transition into parenthood when couples negotiate and experience different work and family arrangements. Finally, an extended study also could investigate changes in gender attitudes across birth order to inform us more details about the impact brought by the birth of a child.

Notwithstanding the above limitations, this study advances our understanding of the dynamics of women's gender attitudes. The finding of a crossover effect of full-time working motherhood and non-working motherhood clarifies the association between motherhood and 
Zhou, Muzhi. 2017. Motherhood, employment, and the dynamics of women's gender attitudes. Gender \& Society. (forthcoming) DOI: 10.1177/0891243217732320

gender attitudes, as well as the association between employment and gender attitudes. These findings highlight the critical role of the emergence and realization of incompatibility between women's employment and childrearing responsibilities in shaping gender attitudes. In fact, women's primary caring responsibilities as mothers, the desire or need to work, and the lack of adequate childcare ultimately create a dilemma for women that is likely to trigger the reformulation of their gender attitudes. The break in women's lives before and after childbirth, particularly the significant transformation of women's economic and family roles, merits further attention to increase compatibility between women's employment and family responsibilities, which in turn could lead to greater gender equality. 
Zhou, Muzhi. 2017. Motherhood, employment, and the dynamics of women's gender attitudes. Gender \& Society. (forthcoming) DOI: 10.1177/0891243217732320

\section{NOTES}

1. I conducted random effects models using a sample that includes people observed for only one wave. The estimated coefficients are similar, but they do not pass the Hausman test. Therefore, the results based on fixed effects models are preferred and reported. The results from Table 6 on individuals who completed at least five waves also demonstrate that the findings are robust to the selection of the number of waves.

2. Disregarding the results from the factor analysis and the Cronbach's $\alpha$ value, to analyze a sample from the BHPS I used a summed score of all the six items as the dependent variable, although the internal reliability of the dependent variable is substantially reduced. The results remain unchanged except that the gross effect of motherhood is slightly stronger.

3. I included the age of the youngest children in the models, but the estimate is not statistically significant as long as employment status is included. I also examined whether the effect of maternal employment varies by birth parity. I did not find that this effect varies substantially by the number of children.

4. Although most people do not change their educational attainment, some acquire higher levels of education during the observational period. Nevertheless, excluding educational variables did not alter the results.

5. The estimates remain stable when choosing people interviewed for different numbers of waves, but the standard errors are smaller when individuals observed for more waves are included. 
Zhou, Muzhi. 2017. Motherhood, employment, and the dynamics of women's gender attitudes. Gender \& Society. (forthcoming) DOI: 10.1177/0891243217732320

\section{REFERENCES}

Allison, Paul D. 2009. Structural equation models with fixed effects. In Fixed effects regression models, edited by Paul D. Allison. Thousand Oaks, CA: Sage Publications.

Barth, Alice. 2016. The changing nature of attitude constructs: An application of multiple correspondence analysis on gender role attitudes. Quality \& Quantity 50 (4):1507-23.

Baxter, Janeen, Sandra Buchler, Francisco Perales, and Mark Western. 2015. A life-changing event: First births and men's and women's attitudes to mothering and gender divisions of labor. Social Forces 93(3):989-1014.

Baxter, Leslie A. and Barbara M. Montgomery. 1996. Relating: Dialogues and dialectics. New York: Guilford Press.

Berrington, Ann, Yongjian Hu, Peter W. F. Smith, and Patrick Sturgis. 2008. A graphical chain model for reciprocal relationships between women's gender role attitudes and labour force participation. Journal of the Royal Statistical Society. Series A (Statistics in Society) 171(1):89-108.

Bohner, Gerd and Nina Dickel. 2011. Attitudes and attitude change. Annual Review of Psychology 62(1):391-417.

Bolzendahl, Catherine I. and Daniel J. Myers. 2004. Feminist attitudes and support for gender equality: Opinion change in women and men, 1974-1998. Social Forces 83(2):759-89.

Boris, Eileen. 1994. Mothers are not workers: Homework regulation and the construction of motherhood. In Mothering: Ideology, experience, and agency, edited by Evelyn Nakano Glenn, Grace Chang and Linda Rennie Forcey. New York: Routledge. 
Zhou, Muzhi. 2017. Motherhood, employment, and the dynamics of women's gender attitudes. Gender \& Society. (forthcoming) DOI: 10.1177/0891243217732320

Boyd, Wendy, Prudence M. Millear, Karen L. Thorpe, and Sue Walker. 2016. Working it out: Balancing work and care after the birth of a first child. In Exploring resources, lifebalance and well-being of women who work in a global context, edited by Roxane L. Gervais and Prudence M. Millear. Switzerland: Springer International Publishing.

Braun, Michael. 2008. Using egalitarian items to measure men's and women's family roles. Sex Roles 59(9):644-56.

Chatterji, Pinka, Sara Markowitz, and Jeanne Brooks-Gunn. 2013. Effects of early maternal employment on maternal health and well-being. Journal of Population Economics 26(1):285-301.

Corrigall, Elizabeth A. and Alison M. Konrad. 2007. Gender role attitudes and careers: A longitudinal study. Sex Roles 56(11):847-55.

Crompton, Rosemary and Clare Lyonette. 2005. The new gender essentialism-domestic and family "choices" and their relation to attitudes. The British Journal of Sociology 56(4):601-20.

Cunningham, Mick, Ann M. Beutel, Jennifer S. Barber, and Arland Thornton. 2005. Reciprocal relationships between attitudes about gender and social contexts during young adulthood. Social Science Research 34(4):862-92.

Davis, Nancy J. and Robert V. Robinson. 1991. Men's and women's consciousness of gender inequality: Austria, West Germany, Great Britain, and the United States. American Sociological Review 56(1):72-84.

Davis, Shannon N. and Theodore N. Greenstein. 2009. Gender ideology: Components, 
Zhou, Muzhi. 2017. Motherhood, employment, and the dynamics of women's gender attitudes. Gender \& Society. (forthcoming) DOI: 10.1177/0891243217732320

predictors, and consequences. Annual Review of Sociology 35:87-105.

Davis, Shannon N. and Sara B. Moore. 2010. Bearing children, becoming mothers: The influence of childbearing on unmarried women's gender ideology. International Journal of Sociology of the Family 36(2):77-91.

Elster, Jon. 2016. Sour grapes: Studies in the subversion of rationality. Cambridge, UK: Cambridge University Press.

Esping-Andersen, Gøsta. 2009. Incomplete revolution: Adapting welfare states to women's new roles. Cambridge, UK: Wiley.

Evertsson, Marie. 2013. The importance of work: Changing work commitment following the transition to motherhood. Acta Sociologica 56(2):139-53.

Fan, Pi-Ling and Margaret Mooney Marini. 2000. Influences on gender-role attitudes during the transition to adulthood. Social Science Research 29(2):258-83.

Festinger, Leon. 1962. A theory of cognitive dissonance. Palo Alto, CA: Stanford University Press.

Gangl, Markus and Andrea Ziefle. 2009. Motherhood, labor force behavior, and women's careers: An empirical assessment of the wage penalty for motherhood in Britain, Germany, and the United States. Demography 46(2):341-69.

Garey, Anita Ilta. 1999. Weaving work and motherhood. Philadelphia, PA: Temple University Press.

Guetto, Raffaele, Ruud Luijkx, and Stefani Scherer. 2015. Religiosity, gender attitudes and 
Zhou, Muzhi. 2017. Motherhood, employment, and the dynamics of women's gender attitudes. Gender \& Society. (forthcoming) DOI: 10.1177/0891243217732320

women's labour market participation and fertility decisions in Europe. Acta Sociologica 58(2):155-72.

Hakim, Catherine. 2000. Work-lifestyle choices in the 21st century: Preference theory. Oxford, UK: Oxford University Press.

Hays, Sharon. 1996. The cultural contradictions of motherhood. New Haven, CT: Yale University Press.

Holland, Jennifer A. and Renske Keizer. 2015. Family attitudes and fertility timing in sweden. European Journal of Population 31(3):259-85.

Johnston, Deirdre D. and Debra H. Swanson. 2006. Constructing the "good mother": The experience of mothering ideologies by work status. Sex Roles 54(7):509-19.

Kaiser, Henry F. 1958. The varimax criterion for analytic rotation in factor analysis. Psychometrika 23(3):187-200.

Kan, Man-Yee. 2007. Work orientation and wives' employment careers: An evaluation of Hakim's preference theory. Work and Occupations 34(4):430-62.

Kanji, Shireen and Emma Cahusac. 2015. Who am I? Mothers' shifting identities, loss and sensemaking after workplace exit. Human Relations 68(9):1415-36.

Kaufman, Gayle, Eva Bernhardt, and Frances Goldscheider. 2016. Enduring egalitarianism? Family transitions and attitudes toward gender equality in Sweden. Journal of Family Issues:1-21.

Killewald, Alexandra and Javier García-Manglano. 2016. Tethered lives: A couple-based 
Zhou, Muzhi. 2017. Motherhood, employment, and the dynamics of women's gender attitudes. Gender \& Society. (forthcoming) DOI: 10.1177/0891243217732320

perspective on the consequences of parenthood for time use, occupation, and wages. Social Science Research 60:266-82.

Kim, Erin Hye-Won and Adam Ka Lok Cheung. 2015. Women's attitudes toward family formation and life stage transitions: A longitudinal study in Korea. Journal of Marriage and Family 77(5):1074-90.

Kroska, Amy and Cheryl Elman. 2009. Change in attitudes about employed mothers: Exposure, interests, and gender ideology discrepancies. Social Science Research 38(2):366-82.

Lersch, Philipp M. 2016. Family migration and subsequent employment: The effect of gender ideology. Journal of Marriage and Family 78(1):230-45.

Lewis, Jane, Trudie Knijn, Claude Martin, and Ilona Ostner. 2008. Patterns of development in work/family reconciliation policies for parents in France, Germany, The Netherlands, and the UK in the 2000s. Social Politics: International Studies in Gender, State \& Society 15(3):261-86.

McDonald, Peter. 2000. Gender equity in theories of fertility transition. Population and Development Review 26(3):427-39.

Mercer, Ramona T. 2004. Becoming a mother versus maternal role attainment. Journal of Nursing Scholarship 36(3):226-32.

Office for National Statistics. 2013. Full report—women in the labour market. Office for National Statistics. Last Modified 25 September 2013. http://www.ons.gov.uk/employmentandlabourmarket/peopleinwork/employmentande 
Zhou, Muzhi. 2017. Motherhood, employment, and the dynamics of women's gender attitudes. Gender \& Society. (forthcoming) DOI: 10.1177/0891243217732320

mployeetypes/articles/womeninthelabourmarket/2013-09-25.

Office for National Statistics. 2014. Families in the labour market, 2014. Office for National Statistics. Last Modified 9 December 2014. http://webarchive.nationalarchives.gov.uk/20160105160709/http://www.ons.gov.uk/o ns/dcp171776_388440.pdf.

Paxton, Pamela and Sheri Kunovich. 2003. Women's political representation: The importance of ideology. Social Forces 82(1):87-113.

Schober, Pia S. 2013a. Maternal labor market return and domestic work after childbirth in Britain and Germany. Community, Work \& Family 16(3):307-26.

Schober, Pia S. 2013b. The parenthood effect on gender inequality: Explaining the change in paid and domestic work when British couples become parents. European Sociological Review 29(1):74-85.

Schober, Pia and Jacqueline Scott. 2012. Maternal employment and gender role attitudes: Dissonance among British men and women in the transition to parenthood. Work, Employment \& Society 26(3):514-30.

Stryker, Sheldon. 1968. Identity salience and role performance: The relevance of symbolic interaction theory for family research. Journal of Marriage and Family 30(4):558-64.

Stryker, Sheldon and Peter J. Burke. 2000. The past, present, and future of an identity theory. Social Psychology Quarterly 63(4):284-297.

University of Essex. 2010. British household panel survey: Waves 1-18, 1991-2009, edited by Institute for Social and Economic Research. SN: 5151. Colchester, Essex: UK Data 
Zhou, Muzhi. 2017. Motherhood, employment, and the dynamics of women's gender attitudes. Gender \& Society. (forthcoming) DOI: 10.1177/0891243217732320

Archive [distributor]. doi:10.5255/UKDA-SN-5151-1.

University of Essex. 2016. Understanding society: Waves 1-6, 2009-2015, edited by Institute for Social and Economic Research and NatCen Social Research. SN: 6614. Colchester, Essex: UK Data Archive [distributor]. doi: 10.5255/UKDA-SN-6614-9.

Vespa, Jonathan. 2009. Gender ideology construction: A life course and intersectional approach. Gender \& Society 23(3):363-87.

Wayne, Julie Holliday, Wendy J. Casper, Russell A. Matthews, and Tammy D. Allen. 2013. Family-supportive organization perceptions and organizational commitment: The mediating role of work-family conflict and enrichment and partner attitudes. Journal of Applied Psychology 98(4):606-22.

Williams, Richard, Paul Allison, and Enrique Moral-Benito. 2015. Linear dynamic panel-data estimation using maximum likelihood and structural equation modeling. Paper presented at 2015 Stata Users Conference, Columbus, Ohio.

Yavorsky, Jill E., Claire M. Kamp Dush, and Sarah J. Schoppe-Sullivan. 2015. The production of inequality: The gender division of labor across the transition to parenthood. Journal of Marriage and Family 77(3):662-79.

Youngblut, JoAnne M. 1995. Consistency between maternal employment attitudes and employment status. Research in Nursing \& Health 18(6):501-13. 
Zhou, Muzhi. 2017. Motherhood, employment, and the dynamics of women's gender attitudes. Gender \& Society. (forthcoming) DOI: 10.1177/0891243217732320

TABLE 1: Results of Principal Factor Analysis for Items Measuring Gender Attitudes

\begin{tabular}{lllcc}
\hline \multirow{2}{*}{ Items } & \multicolumn{1}{c}{ Description } & Surveys & \multicolumn{2}{c}{ Factor Loadings } \\
\cline { 4 - 5 } & & & Factor 1 & Factor 2 \\
\hline 1 & Preschool child suffers if mother works & Both & $\mathbf{0 . 8 1 0}$ & -0.070 \\
2 & Family suffers if woman works & Both & $\mathbf{0 . 8 3 9}$ & 0.049 \\
3 & Women and family are happier if she works & BHPS only & 0.097 & $\mathbf{0 . 5 4 9}$ \\
4 & Husband and wife should both contribute to & & & \\
5 & income & Both & 0.024 & $\mathbf{0 . 6 2 1}$ \\
6 & Full-time job makes women independent & BHPS only & -0.069 & $\mathbf{0 . 6 6 7}$ \\
& Husband should earn, wife stay at home & Both & $\mathbf{0 . 6 0 1}$ & 0.051 \\
& Eigenvalue & & 2.043 & 0.860 \\
& \% of Variance & & 0.791 & 0.571 \\
\hline
\end{tabular}

Note: Factor loading higher than 0.500 are in bold type. 
Zhou, Muzhi. 2017. Motherhood, employment, and the dynamics of women's gender attitudes. Gender \& Society. (forthcoming) DOI: 10.1177/0891243217732320

TABLE 2: Descriptive Statistics for Individuals and for Person-Wave Observations of Women Aged 21 to 45

\begin{tabular}{|c|c|c|c|}
\hline & Childless & Mothers & Overall \\
\hline \multicolumn{4}{|l|}{ Individuals } \\
\hline \multicolumn{4}{|l|}{ Employment Status } \\
\hline Full-time & $90.1 \%$ & $40.4 \%$ & $90.8 \%$ \\
\hline Part-time & $20.0 \%$ & $53.7 \%$ & $39.9 \%$ \\
\hline \multicolumn{4}{|l|}{ Non-working } \\
\hline Maternity & N/A & $21.5 \%$ & \multirow[t]{2}{*}{$35.9 \%$} \\
\hline Other Non-working & $23.4 \%$ & $39.3 \%$ & \\
\hline Number of Individuals & 2,729 & 1,150 & 2,729 \\
\hline \multicolumn{4}{|l|}{ Person-waves } \\
\hline \multicolumn{4}{|l|}{ Traditional Gender Attitude } \\
\hline Score & $6.552(2.399)$ & $7.289(2.679)$ & $6.731(2.481)$ \\
\hline \multicolumn{4}{|l|}{ Employment Status } \\
\hline Full-time & $81.8 \%$ & $25.3 \%$ & $69.4 \%$ \\
\hline Part-time & $8.3 \%$ & $37.7 \%$ & $16.8 \%$ \\
\hline \multicolumn{4}{|l|}{ Non-working } \\
\hline Maternity & N/A & $10.4 \%$ & \multirow{2}{*}{$13.8 \%$} \\
\hline Other Non-working & $9.9 \%$ & $26.6 \%$ & \\
\hline Age & $27.767(6.519)$ & $33.113(4.910)$ & $29.070(6.335)$ \\
\hline \multicolumn{4}{|l|}{ Marital Status } \\
\hline Single and Never Married & $53.0 \%$ & $7.8 \%$ & $42.0 \%$ \\
\hline Cohabiting & $27.1 \%$ & $16.4 \%$ & $24.5 \%$ \\
\hline Married & $16.9 \%$ & $73.1 \%$ & $30.6 \%$ \\
\hline Separated/Divorced/Widowed & $3.1 \%$ & $2.7 \%$ & $3.0 \%$ \\
\hline \multicolumn{4}{|l|}{ Education } \\
\hline GCSE Level or Lower & $21.4 \%$ & $22.1 \%$ & $21.6 \%$ \\
\hline Some Higher Qualifications & $47.8 \%$ & $40.5 \%$ & $46.1 \%$ \\
\hline First Degrees or Above & $30.8 \%$ & $37.4 \%$ & $32.4 \%$ \\
\hline $\begin{array}{l}\text { Number of Person-wave } \\
\text { Observations }\end{array}$ & 9,216 & 3,346 & 12,562 \\
\hline \multicolumn{4}{|c|}{$\begin{array}{l}\text { Notes: The number of women in the sample is } 2,729 \text {. Because there are } 1,150 \text { transitions to } \\
\text { motherhood for the first time, } 1,150 \text { women are included in both the childless and the } \\
\text { mother records. Sums of percentages for discrete variables may differ slightly from } 100 \% \\
\text { because of rounding. }\end{array}$} \\
\hline
\end{tabular}


Zhou, Muzhi. 2017. Motherhood, employment, and the dynamics of women's gender attitudes. Gender \& Society. (forthcoming) DOI: 10.1177/0891243217732320

TABLE 3: Traditional Gender Attitude Score by Motherhood and Employment Statuses

\begin{tabular}{rccccc}
\hline & \multicolumn{5}{c}{ Employment Status } \\
\cline { 3 - 5 } & $\begin{array}{c}\text { Full-time } \\
\text { Working }\end{array}$ & $\begin{array}{c}\text { Part-time } \\
\text { Working }\end{array}$ & $\begin{array}{c}\text { Maternity } \\
\text { Leave }\end{array}$ & $\begin{array}{c}\text { Other Non- } \\
\text { working }\end{array}$ & Overall \\
\hline Motherhood Status & & & & & \\
Childless & 6.874 & 6.92 & N/A & 7.218 & 6.904 \\
& $(2.404)$ & $(2.408)$ & & $(2.511)$ & $(2.414)$ \\
& $5.788^{\mathrm{a}}$ & $7.276^{\mathrm{a}}$ & 6.903 & $8.791^{\mathrm{a}}$ & $7.299^{\mathrm{b}}$ \\
& $(2.264)$ & $(2.408)$ & $(2.574)$ & $(2.567)$ & $(2.679)$ \\
Mothers & 6.592 & $7.267^{\mathrm{c}}$ & \multicolumn{2}{c}{$8.483^{\mathrm{c}}$} & 7.113 \\
& $(2.419)$ & $(2.426)$ & \multicolumn{2}{c}{$(2.639)$} & $(2.564)$ \\
\hline
\end{tabular}

Notes: Means and standard deviations of the traditional gender attitude scores are not weighted. Standard deviations are in parentheses. A five percent level of significance is used.

${ }^{a}$ Indicates that the mean differs statistically significantly from childless full-time workers.

${ }^{\mathrm{b}}$ Indicates that the mean differs statistically significantly from childless women.

${ }^{\mathrm{c}}$ Indicates that the mean differs statistically significantly from full-time workers. 
Zhou, Muzhi. 2017. Motherhood, employment, and the dynamics of women's gender attitudes. Gender \& Society. (forthcoming) DOI: 10.1177/0891243217732320

TABLE 4: Change in the Standardized Score of Traditional Gender Attitudes Associated with Changes in Motherhood Status, Employment Status, and the Interaction between Motherhood Status and Employment Status

\begin{tabular}{|c|c|c|c|c|}
\hline & Model 1 & Model 2 & Model 3 & Model 4 \\
\hline \multicolumn{5}{|l|}{ Motherhood Status } \\
\hline Mother & $\begin{array}{l}0.044^{*} \\
(0.022)\end{array}$ & $\begin{array}{c}0.001 \\
(0.024)\end{array}$ & $\begin{array}{c}-0.187 * * * \\
(0.029)\end{array}$ & \\
\hline \multicolumn{5}{|l|}{ Employment Status } \\
\hline Part-time Working & & $\begin{array}{c}0.012 \\
(0.022)\end{array}$ & $\begin{array}{l}-0.074 * \\
(0.031)\end{array}$ & \\
\hline Non-working & & $\begin{array}{l}0.186 * * * \\
(0.025)\end{array}$ & $\begin{array}{l}-0.033 \\
(0.031)\end{array}$ & \\
\hline \multicolumn{5}{|l|}{$\begin{array}{l}\text { Raw Interaction Between } \\
\text { Motherhood \& Employment }\end{array}$} \\
\hline Mother * Part-time Working & & & $\begin{array}{c}0.300 * * * \\
(0.044)\end{array}$ & \\
\hline Mother * Non-working & & & $\begin{array}{c}0.573 * * * \\
(0.047)\end{array}$ & \\
\hline \multicolumn{5}{|l|}{$\begin{array}{l}\text { Refined Interaction Between } \\
\text { Motherhood \& Employment }\end{array}$} \\
\hline $\begin{array}{l}\text { Childless \& Full-time Working } \\
\text { Childless \& Part-time Working }\end{array}$ & erence) & & & $\begin{array}{l}-0.075^{*} \\
(0.031)\end{array}$ \\
\hline Childless \& Non-working & & & & $\begin{array}{l}-0.033 \\
(0.031)\end{array}$ \\
\hline Mother \& Full-time Working & & & & $\begin{array}{c}-0.212 * * * \\
(0.031)\end{array}$ \\
\hline Mother \& Part-time Working & & & & $\begin{array}{c}0.022 \\
(0.029)\end{array}$ \\
\hline Mother \& Maternity Leave & & & & $\begin{array}{l}-0.004 \\
(0.046)\end{array}$ \\
\hline Mother \& Non-working & & & & $\begin{array}{c}0.350 * * * \\
(0.032)\end{array}$ \\
\hline Person-Wave Observations & 12,562 & 12,562 & 12,562 & 12,562 \\
\hline Individuals & 2,729 & 2,729 & 2,729 & 2,729 \\
\hline
\end{tabular}

Note: All models include age, its square term, wave dummies, education, and marital status. Standard errors are in parentheses.

$* \mathrm{p}<.05 * * \mathrm{p}<.01 * * * \mathrm{p}<.001$ 
Zhou, Muzhi. 2017. Motherhood, employment, and the dynamics of women's gender attitudes. Gender \& Society. (forthcoming) DOI: 10.1177/0891243217732320

TABLE 5: Changes in the Standardized Scores of Traditional Gender Attitudes Associated with Changes in Motherhood Status and Working Conditions for Full-time Workers

Model 1

Model 2

Motherhood Status

Childless (reference group)

Mother

$-0.190 * * *$

$-0.192 * * *$

(0.032)

(0.032)

Employment Sector

Private Sector (reference group)

Non-private Sector

Female Occupation

Self-Employment

(0.063)

Person-Wave Observations

7,838

7,838

Individuals

2,348

2,348

Note: This sample only includes observations of women who work full time and have full information on the variables used. All models include age, its square term, wave dummies, marital status, and educational level. Standard errors are in parentheses.

$* \mathrm{p}<.05 * * \mathrm{p}<.01 * * * \mathrm{p}<.001$ 
Zhou, Muzhi. 2017. Motherhood, employment, and the dynamics of women's gender attitudes. Gender \& Society. (forthcoming) DOI: 10.1177/0891243217732320

TABLE 6: Change in the Standardized Score of Traditional Gender Attitudes Associated with Changes in the Combined Status of Motherhood and Employment

\begin{tabular}{|c|c|c|c|}
\hline & $\begin{array}{l}\text { Conventional } \\
\text { Fixed Effects } \\
\quad(5 \text { waves })\end{array}$ & $\begin{array}{l}\text { Fixed Effects } \\
\text { within SEM } \\
\text { Framework } \\
\text { (5 waves) }\end{array}$ & $\begin{array}{c}\text { Dynamic, } \\
\text { Fixed Effects } \\
\text { with Lagged } \\
\text { Dependent } \\
\text { Variable (5 } \\
\text { waves) }\end{array}$ \\
\hline Lagged Dependent Variable & & & $\begin{array}{c}0.179 * * * \\
(0.020)\end{array}$ \\
\hline \multicolumn{4}{|l|}{$\begin{array}{l}\text { Refined Interaction Between } \\
\text { Motherhood \& Employment } \\
\text { Childless \& Full-time Working } \\
\text { (reference) }\end{array}$} \\
\hline Childless \& Part-time Working & $\begin{array}{c}-0.086 * \\
(0.044)\end{array}$ & $\begin{array}{l}-0.040 \\
(0.050)\end{array}$ & $\begin{array}{l}-0.071 \\
(0.056)\end{array}$ \\
\hline Childless \& Non-working & $\begin{array}{c}-0.020 \\
(0.043)\end{array}$ & $\begin{array}{c}-0.034 \\
(0.052)\end{array}$ & $\begin{array}{c}-0.053 \\
(0.059)\end{array}$ \\
\hline Mother \& Full-time Working & $\begin{array}{c}-0.264 * * * \\
(0.046)\end{array}$ & $\begin{array}{c}-0.244 * * * \\
(0.046)\end{array}$ & $\begin{array}{c}-0.184 * * \\
(0.071)\end{array}$ \\
\hline Mother \& Part-time Working & $\begin{array}{l}-0.005 \\
(0.042)\end{array}$ & $\begin{array}{c}0.005 \\
(0.042)\end{array}$ & $\begin{array}{c}0.078 \\
(0.116)\end{array}$ \\
\hline Mother \& Maternity Leave & $\begin{array}{l}-0.055 \\
(0.065)\end{array}$ & $\begin{array}{c}-0.064 \\
(0.063)\end{array}$ & $\begin{array}{c}-0.07 \\
(0.104)\end{array}$ \\
\hline Mother \& Non-working & $\begin{array}{c}0.366^{* * * *} \\
(0.045)\end{array}$ & $\begin{array}{c}0.364 * * * \\
(0.045)\end{array}$ & $\begin{array}{c}0.297 * * \\
(0.116)\end{array}$ \\
\hline Person-Wave Observations & 6,210 & 6,210 & 6,210 \\
\hline Individuals & 1,242 & 1,242 & 1,242 \\
\hline
\end{tabular}

Note: Each woman has five person-wave records in this sample. All models include age, its square term, marital status, and education levels. Standard errors are in parentheses.

$* \mathrm{p}<.05 * * \mathrm{p}<.01 * * * \mathrm{p}<.001$ 
Zhou, Muzhi. 2017. Motherhood, employment, and the dynamics of women's gender attitudes. Gender \& Society. (forthcoming) DOI: 10.1177/0891243217732320

FIGURE 1: Comparison of the Effect Sizes of Employment Status for Childless Women and Mothers
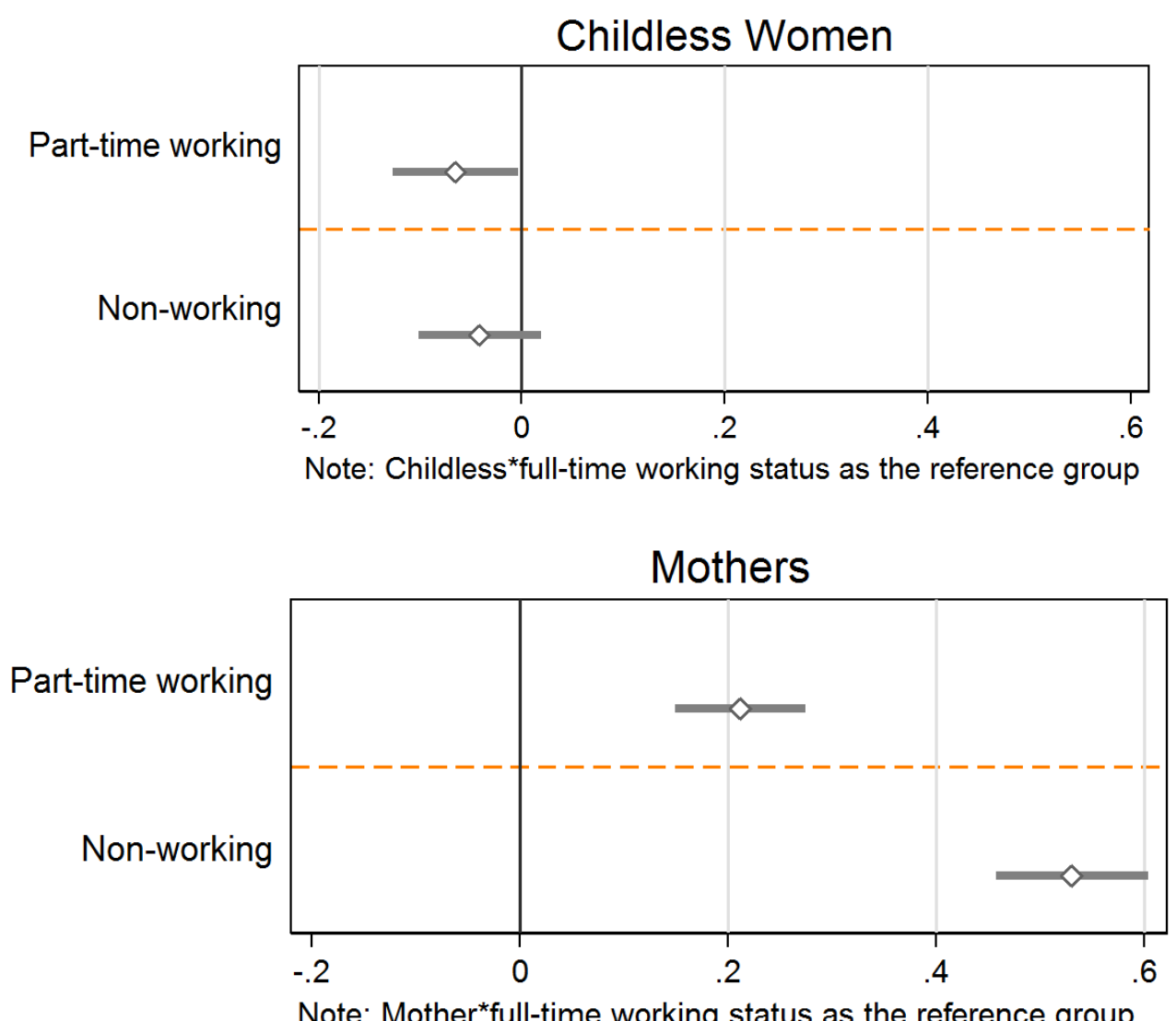

Source: Model 3 of Table 4 
Zhou, Muzhi. 2017. Motherhood, employment, and the dynamics of women's gender attitudes. Gender \& Society. (forthcoming) DOI: 10.1177/0891243217732320

Muzhi Zhou is a PhD student in the Department of Sociology at the University of Oxford. She is also affiliated with St Antony's College. Her areas of interest include gender, family and marriage, and quantitative methodology. Her recent research examines the gendered effect of parenthood and the relationship between gender equality and fertility. 